Science, which began in a January number the publication of a series of articles by one of the naturalists who accompanied the steamer. ${ }^{1}$ Coming from such an authoritative source, we are led to regard these papers almost in the light of a semi-official report, and look to them for at least a correct statement regarding the origin of their methods of work, inasmuch as these matters are discussed in some detail, and with evident pride at the completeness of the outfit. That the outfit was complete no one who is at all posted on the subject can deny; for nearly all of the many improvements introduced by the Coast Survey and Fish Commission prior to 1880 are most faithfully copied, and most heartily praised for their perfect adaptation to the requirements of research.

We glance through the several pages of the report for at least some slight acknowledgment on behalf of American inventive skill ; but beyond a brief statement to the effect that the hoistingengine "was of the same type as that employed by Mr. Agassiz," and that he also " used with good results the common form of beam-trawl," we are left to infer that the entire outfit was of French origin; and such must be the impression of every one who reads these papers. In fact, in several instances, credit is explicitly bestowed on French inventors for certain of the appliances which do not differ in any essential features from the corresponding American patterns.

What is to be gained by thus appropriating to the credit of a nation what properly belongs to another and a friendly one, by all the rights of international courtesy, it is difficult to understand, and especially so in this age of supposed enlightenment, when every important discovery is carried with lightning rapidity to all parts of the civilised world. The field of marine research is sufficiently broad to engage the entire attention of all the naturalists who have yet entered it ; and the frequent manifestations of jealousy on the part of foreign, and especially French, investigators, which often result in wholly ignoring the works of an able American author, can but retard progress instead of aiding it.

Proofs of the superior excellence of American methods of deep-sea research may be found in every important scientific library of Europe as well as this country ; and at the two most prominent International Fisheries Exhibitions of the worldthose of Berlin in 1880 , and London in 1883 - all of the American appliances were displayed, and received the highest awards. They have therefore been made sufficiently well known to establish their merits before the scientific world; but, as no descriptions of them have yet been published for the benefit of the general public, we propose in future numbers of Science to give accounts of their construction, and of the causes which lead to their introduction.

RICHARD RATHBUN

\section{WHY TROPICAL MAN IS BLACK}

THERE are few subjects the explanation of which has taxed the ingenuity of man more than the existence of extremes of colour in different sections of the human race. Tradition has attributed the dark race to one of three brothers, the other two being progenitors of the opposite hue, without at the same time offering any solution of the variation from a common stock.

Physiologists have vaguely asserted that a black skin is best suited to a hot climate, but do not attempt to reconcile the fact that a black coat is certainly the least adapted to the same condition. Evolutionists would doubtless say that in those early days when man in the dense forests of the time was fighting his brave struggle of brain against fangs and claws, the dark skin mingling with the shadows of the overhanging foliage gave him a chance of survival ; but this reaches the conclusion that the first men were black, and that all white men proceeded out from these.

Yet even if this be so, and if the dark skin served only for concealment, why on the burning tablelands and treeless undulations of Central and Southern Africa, where there is scarce a bough to shelter him, has man for so many thousand years preserved a colour which has become the standard of all blackness? Surely there must be some other explanation of the fact that man beneath the vertical rays of a tropic sun has persisted in maintaining a hue of skin which would appear to have the effect only of absorbing and accumulating the intense heat of his surroundings. Some reason why the ryot of India can labour in the plains

I For an abstract of the portion relating to the apparatus employed, see Science, No. 62. clad only in the scantiest loin-cloth, and why the African can limit his full dress to a few inches of monkey-tails.

The rapidly accumulating evidence of the practical utility of every peculiarity, and the proofs that nature, by hoarding up a little of each individual advantage through countless generations, has arrived at the best condition for each environment, compe us to realise the fact that in the tropics darkness of skin contributes to survival.

That this colour will absorb heat more than any other is as true of the skin of a man as of the roof of a house; therefore the anomaly is reached that in the tropics he is fittest who is hottest, so long as heat is regarded as the only factor in the consideration. But that one cannot live by heat alone is as true of the animal kingdom as of the whole vegetable world. Light, the twin stimulant of life, because perceptible to out consciousness by its action on a specialised nerve, has been too much limited in our conceptions of its influence to that duty only.

The gigantic processes of nature by which the great vegetable world, past and present, has been built up, the oxygen of water divorced from its hydrogen in the leaves of plants, and carbonic acid resolved into its constituents, were and are accomplished by the light-waves of the sun; and yet in the animal kingdom the action of these waves upon the eye is held to be almost their sole effect.

The craning offshoot of a window-plant, the twisted leaves of an indoor flower are sufficient evidence of the resistless power of light, and the proofs of its effect on man are as numerous as those of its action on plants; the mode only of that action is the mystery, and yet if this can be even partially explained, enough may be attained to show why those in whom a portion of the rays of the glaring tropic sun are blocked at the surface are best adapted for survival beneath its vertical beams.

As has been expressed by Prof. Tyndall ("Atoms, Molecules, and Ether Waves," Longman's Magazine, Nov. I882) "We know that all organic matter is composed of ultimate molecules made up of atoms, and that these constituent atoms can vibrate to and fro millions and millions of times in a second." Nerve is organic matter, and "whether we meet with nerve tissue in a jelly fish, an oyster, an insect, a bird or a man, we have no difficulty in recognising its structural units as everywhere more or less similar. These structural units are microscopic cells and microscopic fibres, the function of the fibres is that of conducting impressions (represented by molecular movements) to and from the nerve cells, while the function of the cells is that of originating those of the impressions which are conducted by the fibres outwards," (vide "Mental Evolution in Animals," Romanes).

We can conceive then that the way in which a nerve-fibre conveys to a more central nerve-cell an impression from the surface is by rapid vibration of its component molecules. Such vibrations can be rudely originated by contact, pressure, or such like stimuli, till they give rise to feeling, or, if severe, to pain, but they can be not only improvised, they can be communicated. The simplest illustration of vibrations being communicated is when a piano is opened and sung into; whereupon the string whose tension coincides with the uttered note will take it up and pass it on in sound. If then vibrations were taking place in the immediate vicinity of the sentient extremities of nerves all over the surface of the body, the same would be expected to occur.

The waves of light and heat follow each other at similar rates through the luminiferous ether.

Man lives at the bottom of a measureless ocean of this subtle medium, and is, in common with all else in the universe, permeated by it. "When, therefore, light or radiant heat impinge, like the waves of sound just adverted to, their waves select those atoms whose periods of vibration synchronise with their own periods of recurrence, and to such atoms deliver up their motion. It is thus that light and radiant heat are absorbed." (Tyndall).

Is it not from this easily intelligible how heat-waves notify their existence and intensity along the surface fibre to the central nerve cell, and so enable the animal to avoid their action, if excessive, or seek their increase, when deficient. And shall it be said that while the heat-waves are thus received, and responded to, through every instant of existence, their fellowworkers, the waves of light, are practically inert except for the stimulation of the one specialised nerve of the eye?

By going from the complicated and compound to the structureless and simple, the question can be answered in no uncertain 
In some of his recently published experiments, Engelmann found that many of the protoplasmic and unicellular organisms are affected by light, and when the first animals possessed of organs of special sense, viz., the jelly-fish, (Medusæ), are reached it is found that one particular Medusa (Tiaropsis polybiademata) always responds to strong luminous stimulation by going into a spasm or cramp (Romanes).

But there is a still stronger argument in favour of the powerful action of light on the nerves of the skin in the fact that, as Prof. Hceckel says, "the general conclusion has been reached that in man, and in all other animals, the sense organs as a whole arise in essentially the same way, viz. as parts of the external integument, or epidermis." In fact, that nerves which now see could once but feel. That the highly sensitive optic nerves are but nerves of the skin, whose molecules once could vibrate only in consonance with the large ultratred waves of heat, whereas now their molecules have become attuned to the shorter waves of the visible part of the spectrum.

Surcly, then, if any one of the nerve-endings of the skin indiscriminately can be specialised for the recognition of light, whether at the margin of the swimming disk in the jelly-fish, at the point of the ray in the star-fish, on the fringe of the mantle in the shell-fish, or on the back in some species of snail, it must be conceded that in the first instance all surface nerves must feel the influence of that agent by which they are to be hereafter exalted. And this has been reduced to a demonstration by $\mathrm{Mr}$. Darwin in his investigations on earthworms, which, although destitute of eyes, are able to distinguish with much rapidity between light and darkness, and as only the anterior extremity of the animal displays this power he concludes that the light affects the anterior nerve-cells immediately, or without the intervention of a sense-organ. But a yet more wondrous lesson is to be learned from the steps which Nature takes for the exaltation of a heat-responding nerve into one capable of vibrating in harmony with the shorter waves of light.

The only external agents available are heat and light, and by these, with such local adaptations as are possible, the conversion must be brought about.

Seeking again from the lowest organisms the secrets of the highest, it has been found by Engelmann that the simplest creature which responded to luminous stimulation was the protoplasmic Enclena viridis; moreover, that it would only do so if the light were allowed to fall upon the anterior part of the body. Here there is a pigment spot, but careful cxperiment showed that this was not the point most sensitive to light, a colourless and transparent area of protoplasm lying in front of it being found to be so.

From this, the most rudimentary, through the pigmental bodies round the margin of the swimming disk of medusæ, and the pigmented ocelli at the tips of the rays in star-fish, to the lowest vermes, in which Prof. Haeckel finds the usual cells sensitive to light separated by a layer of pigment cells from the outer expansion of the optic nerve, we meet with the same arrangement ever progressing upwards, viz., transparency immediately in front of the part to be exalted, and pigment immediately behind it, and are left to infer from the object ultimately attained wrat is the reason of this primary adaptation.

Nature has made the most of her two factors, by exposing the selected tissue to the continued impinging upon it of the waves of light, while at the same time securing not only the transmission through it of the waves of heat, but their constant accumulation behind it, thereby causing the molecular constituents of the protoplasm to be thrown into the bighest rates of vibration possibly obtainable with the means at disposal, and undoubtedly more rapid than those of any protoplasm not so situated; till little by little, by the survival here and there of individuals who had derived some benefit from inherited increase of sensitiveness in the exposed parts, the time arrived when the advantage became permanent in the species, and the foundation was laid in a transparent atom of protoplasm lying in front of a speck of pigment, of those wondrous organs which in rons of ages afterwards were to enable man to look upon the universe and to behold that it was good.

Such is what light and heat in unison have wrought, and is it to be supposed that their action on the surface nerves is less powerful now than ever? Is it not more reasonable to think that a larger number of specialised nerves not being an advantage have not been developed, and that though we are unconscious of the power of light upon our bodies, yet that analogy points to the fact that to it, when combined with heat, we owe the highest exaltation of our keenest sense?
Recognising thus the effects of simultaneous light and heat when their influence is concentrated by a local peculiarity on a particular part, must it not be evident that in an individual unprotected by hair and unscreened by clothes, living beneath the vertical rays of an equatorial sun, the action of these two forces playing through a transparent skin upon the nerve-endings over the entire surface of the body, must be productive of intense, but at the same time disadvantageous, nerve vibrations, and that presumably such individuals as were least subject thereto would be best adapted to the surroundings?

Nature, therefore, having learned in agcs past that pigment placed behind a transparent nerve will exall its vibrations to the highest pitch, now proceeds upon the converse reasoning, and placing the pigment in front of the endangered nerve reduces its vibrations by so much as the interrupted light would have excited, a quantity which, though apparently trifling, would, when multiplied by the whole area of body-surface, represent a total of nervous action that if $\mathrm{c}$ ntinued would soon exhaust the individual and degrade the specics.

Thus it is that man, though so many generations have come and gone since the days of his weaponless struggles with the beasts of the forest, still e etains in its full strength that colour of skin which, while it aided him materially in his early escapes, is now continued because it has a more important office to fulfil in warding off the millions of vibrations a second which would otherwise be poured in an uninterrupted stream upon his exposed nervous system.

Again, the chemical power of light expressed in degree is, according to Professor Bunsen in Berlin, on the 2Ist of June at I2 o'clock, $38^{\circ}$, while at the same place and time on the $2 \mathrm{Ist}$ of December it is but $20^{\circ}$, that is, that the difference in the angle at which light strikcs the same spot in December and in Tune causes its chemical effect to be almost cloubled. What then must be its potential clifference all the year round in the latitudc of London and in that of Sierra Leone?

If, therefore, light be a necessary factor in the development of animal life, and be of sufficient intensity to attain the required end in the northern position of England, it must of necessity be at the equator immensely in excess, all other things being equal of what is needed, and it would be a reasonable expectation that could unclothed man be traced through the parallels of latitude northwards in distinct tribes that never intermingled with those beyond, the colour of the various sections would lessen in direct proportion to their distance from the equator, modified only by such local conditions as materially influenced the effect of light, or the action of light and heat combined.

And this is forcibly corroborated by the facts put forward in Carpenter's "Physiology," p. 985 : "It may be freely admitted that among European colonists settled in hot climates such changes do not present themselves within a few generations; but in many wcll-known instances of earlier colonisation they are very clearly manifested."

"Thus the wide dispersion of the Jewish nation and their remarkable isolation, maintained by their religious observances from the people among whom they live, render them peculiarly appropriate subjects for such observations, and we accordingly find that the brunette complexion and dark hair which are usually regarded as characteristic of that race are frequently superseded in the Jews of Northern Europe by red or brown hair and fair complexion, whilst the Jews who settled in India some centurie ago have become as dark as the Hindoos around them."

Finally, there is in a footnote to the same page an extraordinary physiological demonstration of the truth of the proposition that skin colour is in direct proportion to light-rays, which is as follows :-

"A very curious example of change of colour in a negro has been recorded on unquestionable authority. The subjcct of it was a negro slave in Kentucky, ret. forty-five, who was born of black parents, and was himself black until twelve years of age. $\Delta$ that time a portion of the skin an inch wide encircling the cranium just within the edge of the hair gradually changed to white, also the hair occupying that locality; a white spot next appeared near the inner canthus of the left eye, and from this the white colour gradually extended over the face, trunk, and extremities until it covered the entire surface. The complete change from black to whitc occupied about ten years, and but for his hair, which was crisp and woolly, no one would have supposed at this time that his progenitors had offered any of the characteristics of the negro--his skin presenting the healthy vascular appearance of a fair-complexioned European. When he was about twenty-two years of age, however, dark copper- 
coloured or brown spots began to appear on the face and hands, but these remained limitid to the portions of the surface exposed to light."

May it not therefore be claimed that there is much foundation for the suggestion that the black skin of the negro is but the smoked glass through which alone his widespread sentient nerveendings could be enabled to regard the sun?

$$
\text { NATHANiel AlCOCK, }
$$

Surgeon-Major, Army Medical Department.

Since the foregoing was written there has appeared in the British Medical Journal, July 26, a most valuable paper by Dr. Gresswell on "Some Effects of Variations of Light," which sum. up in these words, "We are tempted to conclude that light and heat impose each its own effects upon plants, as they do upon animals,", and that "light is a stimulus direct as well as indirect."

\section{SCIENTIFIC SERIALS}

Atti della R. Accademia dei Lincei, May 18. -On the molybdate of didymium, by Alfonso Cossa. - On the geological constitution of the Maritime Alps, by D. Zaccagna.-On some psychological difficulties that may be solved by means of the idea of the infinite, by Francesco Bonatelli.--Remarks on the Oriental manuscripts of the Marsigli Collection at Bologna, with a complete list of the Arabic manuscripts in the same collection, by Baron Victor Rosen.-The Ligurians associated with the barrows of the first Iron Age found in the district of Golasecca, Lombardy, by Luigi Pigorini. - Note on Bartolomeo da Parma, an astronomer of the thirteenth century, and on a treatise by him on the sphere preserved in the Victor Emmantiel Library, by Enrico Narducci.Report on the antiquities discovered in various parts of Italy during the month of April, by S. Fiorclli.-Meteorological observations made at the Observatory of the Campidoglio during the month of April.

June 1.-Obituary notice of A. Wurtz, by S. Camizzaro.On the expansion of sulphuric ether under various pressures, by G. Pietro Grimaldi.-On the physiology and pathology of the supra-renal capsules, by Guido Tizzoni. - Analysis of a silicated hydrate of baryta, by Alfonso Cossa and Guiseppe La Valle. On the observations of atmospheric electricity made at the Central Meteorological Office, Rome, by Pietro Tacchini.Meteorological observations made at the Observatory of the Campidoglio during the month of May.

June 15.--Description of a Buddhist Codex in the Pali language, forwarded to the Academy by L. Nocentini, Italian Vice-Consul at Shanghai.-Obituary notice of Hermann Ulrici, by $\mathrm{S}$. Ferri.-Reports on the influence of heat and magnetism on the electric resistance of bismuth, by Prof. Augusto Righi; on the constants of refraction, by Dr. R. Nasini; on the capillary equivalents of simple bodies, by Prof. R. Schiff.-Note on a problem in electrostatics, by Vito Volterra.-A method of determining the ohm in absolute measure, by Guglielmo Mengarini.-Experimental researches on the variation in the density of water between $0^{\circ}$ and $10^{\circ}$, by Filippo Bonetti.-On the spectrum of absorption of the vapour of iodine, by Arnolfo Morghen. -Remarks on Shelford Bidwell's new explanation of Hall's phenomenon, by Augusto Righi.-. On the electric conductivity of the combinations of carbon, by Adolfo Bartoli.--On the penetrability of glass by gases under pressure, by Adolfo Bartoli.On the coexistence of differentigempirical formulas, and especially on those containing the capillary constant of liquids or the cohesion of solids, by Adolfo Bartoli.-On the atmospheric waves produced by the Krakatoa eruption, and observed at Palermo, by Gaetano Cacciatore. - Remarks on the dynamics of storms, by Ciro Ferrari.- On the intestinal canals and branchial tubes of the Salpida, by Francesco Todaro.--Report on the antiquities found in various parts of Italy during the month of May, by S. Fiorelli.

Rezue d'Anthropologie, tome viii., fasc. 3, Paris, 1884 .-The contents are : - An unfinished paper of Paul Broca, on his mode of preparing the cerebral hemispleres, which, with another chapter on the best methods of casting the required moulds, was to have formed part of the trcatise on the circonvolutions of the schematic brain, on which he was engaged at the time of his death. The present paper breaks off in the middle of his explanation of the process of mummifying the brain.-An essay on the ethnology of North Africa, by M. Camille Sabatier. This paper is entirely devoted to the consideration and recapitula- tion of the geographical descriptions given by Herodotus, Sal lust, and other ancient writers of Lybia, under which designation most of the then known $\Lambda$ frican continent was included. It also treats of the great invasions from Asia, and of the differences between the various African races. As distinct from the Lybians or mountaineers, and the Getulæ or pastoral occupants of the plains, the author believes we may recognise a separate branch, which bore the name of Escs or Oscs, and which probably have given origin to the modern Basque Escualdunacs and other kindred western races. - A continuation of $M$. Deniker's observations on the Kalmuks. This paper is devoted specially to the sociology of the people, the condition of the women, and the practices observed at betrothals, marriages, \&c., being fully treated of, The Lamas, who exercise a great influence on the people--intervening in all the great events of life from the cradle to the grave-are employed in several of the steppes by the Russian Government to keep the civil registers of the various hordes.

On various skulls of Arizona and New Mexico, by M. Ten Kate. From a comparative study of these and other crania collected by the author in his extensive travels in the Far West and in the Mexican territories, he is inclined to regard the constructors of the casas grandes of Arizona and the "cliff-dwellers "as closely allied to the Indian tribes of the Pueblos, or so-called "towns" of New Mexico. He found the same brachycephalic characteristics and the same evidence of artificial deformity in skulls of the ancient Pueblos of Quarra as in the modern Mexican Indians.-On the circumference of the thorax, and its relation to the dimensions of the rest of the body, by M. Ed. Goldstein. This paper is based on the data supplied by Dr. Snigerev in his great work on the recruiting of the Rus sian army, more especially in the districts of the Vistula and the north-west of the empire. The great ethnological fact established by these determinations appears to be that, as compared with Poles, Germans, Lithuanians, Russians, and Samogitians, the Jews are distinguished by relative smallness of stature, and by the generally inferior dimensions of the chest, in both of which particulars they would appear to fall considerably below the mean of all the other races brought under the notice of the authorities at the head of the department for recruiting the Russian army.

Rendiconti del Reale Istituto Lombrardo, July $17 .-$ Note on the present conditions of the agricultural interests in Europe and America (continued), by Prof. Gaetano Cantoni.-Memoir on cellules and parasites in their pathological relations (concluded), by Prof. G. Sangalli.--Mental affection of Torquato Tasso; his detention in the Hospital of Sant' Anna, according to some recently-discovered documents, by Prof. A. Corradi-On the equilibrium of elastic and rigid surfaces, by Dr. Gian Antonic Maggi.

\section{SOCIETIES AND ACADEMIES EDINBURGH}

Royal Society, July 2I.-The Right Hon. Lord Mon. creiff, President, in the chair.-Mr. John Murray communicated, with remarks, a paper by Dr. Guppy of H.M.S. Lark, on the coral reefs and calcareous formations of the Solomon Group Islands. Dr. Guppy showed that the coral rocks were merely superficial, thus confirming Mr. Murray's theory that coral atolls and barrier reefs were formed without subsidence. $\Lambda$ chalk, like the white chalk of England, had been discovered on one of the islands. - Prof. Tait gave an approximate empirical formula representing, for certain ranges, the compressibility of water in terms of the temperature and pressure--Mr. J. T. Cunningham read a critical note on the latest theory in vertebrate morphology,-Mr. Milne Home submitted the tenth and final report of the Boulder Committee. At some period, geologically recent in the earth's history, an Arctic climate prevailed in the part of Northern Europe considered. As an effect, local glaciers occurred in Scotland, of some of which there were traces still visible. Subsequently Scotland was entirely submerged beneath the sea, and most of the valleys were filled with sand, gravel, and mud. A north-westerly oceanic current prevailed, carrying masses of floating ice with boulders, which were deposited on the hills.Mr. H. R. Mill gave a paper on the periodic variation of temperature in tidal basins.- Mr. W. Peddie gave a communication on the isothermals and adiabatics of water near the maximum density point.-The meeting, which was the last for the session, was brought to a close by remarks from the Chairman on the. work of the past session. 